\title{
Editorial: New Trends in Food Processing: Reducing Food Loss, Waste, and the Environmental Impact
}

\author{
Guadalupe Virginia Nevárez-Moorillón ${ }^{1 *}$, Zainul Akmar Zakaria², \\ Lilia Arely Prado-Barragán ${ }^{3}$ and Cristóbal N. Aguilar ${ }^{4}$
}

' Facultad de Ciencias Químicas, Universidad Autónoma de Chihuahua, Circuito Universitario S/N, Campus Universitario II, Chihuahua, Mexico, ${ }^{2}$ Faculty of Engineering, School of Chemical and Energy Engineering, Universiti Teknologi Malaysia, Johor Bahru, Malaysia, ${ }^{3}$ Biological and Health Sciences Division, Biotechnology Department, Iztapalapa Unit, Metropolitan Autonomous University, Mexico City, Mexico, ${ }^{4}$ Bioprocesses and Bioproducts Research Group, Food Research Department, School of Chemistry, Universidad Autónoma de Coahuila, Saltillo, Mexico

Keywords: circular economy, integrated process design, food safety, functional ingredients, biorefinery

\section{OPEN ACCESS}

Edited and reviewed by:

José Antonio Teixeira,

University of Minho, Portugal

*Correspondence:

Guadalupe Virginia Nevárez-Moorillón vnevare@uach.mx

Specialty section:

This article was submitted to

Sustainable Food Processing, a section of the journal

Frontiers in Sustainable Food Systems

Received: 17 January 2022

Accepted: 28 January 2022

Published: 22 February 2022

Citation: Nevárez-Moorillón GV, Zakaria ZA, Prado-Barragán LA and Aguilar CN (2022) Editorial: New Trends in Food

Processing: Reducing Food Loss, Waste, and the Environmental Impact. Front. Sustain. Food Syst. 6:856361. doi: 10.3389/fsufs.2022.856361
Editorial on Research Topic

New Trends in Food Processing: Reducing Food Loss, Waste, and the Environmental Impact

Worldwide, current disposal and poor management of food agroindustrial waste have negatively impacted the environment and the social and economic sectors. Current strategies for food waste management, including disposition in landfills, incineration, composting, and animal feeding, are not considered sustainable or environmentally friendly strategies. Also, these management strategies take part of the social sector due to some respiratory health diseases that can be emerged from the toxic pollutants liberated into the air, decreasing human life quality. Food processing and preservation processes are vital for providing safe and nutritious food products. Among the Sustainable Development Goals (SDG) proposed by the United Nations in 2015, "Zero Hunger" (SDG 2.0) is related to this purpose. However, it is also essential to consider the balance between using natural resources used for food production, and the equilibrium needed to assure sustainability. Food production is among the most demanding human activities on earth resources; therefore, other SDGs are also related to Sustainable Food Production. In SDG 12, "Ensure sustainable consumption and production patterns" indicator 12.3 is related to reducing food loss and waste worldwide, including food production, postharvest, processing, distribution, and consumer consumption.

Sustainable food processing is in constant need of innovation for processes aimed at increasing shelf life while keeping the nutritional and sensorial food properties. Novel food processing approaches incorporate not only technological aspects but also economic and environmental impacts. A circular economy approach will consider the re-utilization of food waste products and the life cycle assessment of food products, including the final disposition of packing materials. As with many other areas of research and development, sustainable food processing proposals need to be multidisciplinary.

Therefore, this Research Topic aimed to provide a discussion platform for interdisciplinary research on the reduction of food loss and waste and the environmental aspects related to innovations in food processing. The articles included in the Research Topic are related to the valorization of food waste products and consideration of the life cycle of food products and equipment. 
Recently, extensive research has been done related to the extraction and purification of functional ingredients from food waste products, which contributes to reducing the environmental impact of food processing and consumption. Arias-Roblero et al., from the University of Costa Rica, proposed Banana Pulp as a substrate to produce a microbial polymer, polyhydroxybutyrate (PHB), by fermentation. Besides providing a solution to an environmental problem as the one-use of plastics for food packing, using food waste products reduces the environmental impact of the banana production industry. The use of brewer's spent grains from the brewery industry is proposed as a source of bioactive compounds in pharmacy. The review was communicated by the group of Tecnológico de Monterrey, México (Macias-Garbett et al.). It included evaluating different methods for the extraction and purification of polyphenols from brewer's spent grains, with a focus on green chemistry alternatives. The concept of biorefinery is discussed, as the use of agroindustrial waste to obtain valuable chemicals is under this concept.

Among the most widespread contaminants related to agriculture are pesticides and fertilizers, which contaminate freshwater and sediments and soils. Some agrochemical residues are environmentally persistent, with the consequent risk to animals and humans. Still, farmers need to use those agrochemicals to increase food production. The environmental impact of the use of agrochemicals in Thailand related to the production of durian fruit was evaluated by Pibul and Jawjit, using two approaches; by collecting information from farmers on the use of agrochemicals and detection of herbicides in waterbodies. The authors suggest using a reporting system that can serve as a basis for reorientation into sustainable agriculture.

The environmental impact of food production can be estimated by using the Life Cycle tool; in Madrid-Solórzano et al., the authors applied the methodology to the production of Sotol in Mexico. Sotol is a distilled alcoholic beverage produced mainly by small factories, using traditional methods. In order to generate an industrial process with minimal environmental impact, the steps that have the highest carbon footprint was identified. This information can be used further by the sotol producers. The equipment used in food processing also has a limited life cycle. In an interesting contribution, Ojide et al. analyzed the use of flash drying equipment in Nigeria used for the production of casava-derived products. Based on information obtained by interviews, the main problems related to the discontinuous use of the equipment were detected, as well as the opportunity for optimized equipment with the same technology.

Even though the subject of the documents included in this Research Topic varies in their objectives, it can be considered a perfect example of the diversity of themes that need to be addressed regarding the design of food processing methods. Most importantly, research needs to be multidisciplinary and include economic, environmental, and societal perspectives. There are still many knowledge gaps in reducing food loss and waste and for the re-engineering of food processing plants.

\section{AUTHOR CONTRIBUTIONS}

All authors listed have made a substantial, direct, and intellectual contribution to the work and approved it for publication.

\section{ACKNOWLEDGMENTS}

The authors thank Frontiers for all their support.

Conflict of Interest: The authors declare that the research was conducted in the absence of any commercial or financial relationships that could be construed as a potential conflict of interest.

Publisher's Note: All claims expressed in this article are solely those of the authors and do not necessarily represent those of their affiliated organizations, or those of the publisher, the editors and the reviewers. Any product that may be evaluated in this article, or claim that may be made by its manufacturer, is not guaranteed or endorsed by the publisher.

Copyright (c) 2022 Nevárez-Moorillón, Zakaria, Prado-Barragán and Aguilar. This is an open-access article distributed under the terms of the Creative Commons Attribution License (CC BY). The use, distribution or reproduction in other forums is permitted, provided the original author(s) and the copyright owner(s) are credited and that the original publication in this journal is cited, in accordance with accepted academic practice. No use, distribution or reproduction is permitted which does not comply with these terms. 